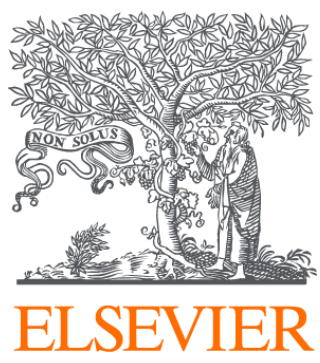

Since January 2020 Elsevier has created a COVID-19 resource centre with free information in English and Mandarin on the novel coronavirus COVID-

19. The COVID-19 resource centre is hosted on Elsevier Connect, the company's public news and information website.

Elsevier hereby grants permission to make all its COVID-19-related research that is available on the COVID-19 resource centre - including this research content - immediately available in PubMed Central and other publicly funded repositories, such as the WHO COVID database with rights for unrestricted research re-use and analyses in any form or by any means with acknowledgement of the original source. These permissions are granted for free by Elsevier for as long as the COVID-19 resource centre remains active. 


\title{
Transfusion medicine: Overtime paradigm changes and emerging paradoxes
}

\author{
O. Garraud ${ }^{\mathrm{a}, \mathrm{b}, *}$, T. Vuk ${ }^{\mathrm{c}}$, M. Lozano ${ }^{\mathrm{d}}$, J.-D. Tissot ${ }^{\mathrm{e}}$ \\ a Université de Lyon Saint-Étienne, 10, rue Tréfilerie, 42023 Saint-Etienne Cedex 2, France \\ ${ }^{\mathrm{b}}$ Institut National de la Transfusion Sanguine, 6, rue Alexandre Cabanel, 75015 Paris, France \\ ${ }^{\mathrm{c}}$ Croatian institute of transfusion medicine, Petrova ul. 3, 10000 Zagreb, Croatia \\ d Clinic university hospital Barcelona, university of Barcelona, 170C. de Villarroel, 08036 Barcelona, Spain \\ e Faculté de biologie et de médecine, université de Lausanne, 21, rue du Bugnon, 1011 Lausanne, Switzerland
}

\section{A R T I C L E I N F O}

\section{Article history:}

Available online 6 October 2020

\section{Keywords:}

Blood transfusion

Transfusion services

Transfusion history

Blood donation

ethics

Blood safety

Hemovigilance

Quality of medicines

Public health

\begin{abstract}
A B S T R A C T
This essay aims to discuss some aspects of blood transfusion in the perspective of the changes that occurred over time as well as modifications of the paradigms that transformed the activities and the organization of blood transfusion services. Without specific knowledge, pioneers envisioned precision and personalized medicine, rendering transfusion medicine operational. Transfusion medicine is like The Picture of Dorian Grey: always young despite being old and sometimes appearing old-fashioned. Over the years, the transfusion medicine discipline has evolved, and major progress has been achieved, despite some troublesome periods (for example, the tainted blood scandal, and-at the time being-the offending plasma market and the selling of human parts). Transfusion medicine has at all times implemented the rapidly developing biomedical technologies to secure blood components. The safety of blood components has now reached an exceptional level in economically wealthy countries, especially compared to other health care disciplines. Strengthening of the safety has mandated that blood donors and recipients are unrelated, an issue which has eased preservation and fractionation practices; blood is no longer arm-toarm transfused and neither is whole blood, the commonest component. However, it is interesting to note that a revival is occurring as whole blood is back on stage for certain specific indications, which is one among the many paradoxes encountered while studying this discipline.
\end{abstract}

(c) 2020 Société française de transfusion sanguine (SFTS). Published by Elsevier Masson SAS. All rights reserved.

\section{Introduction}

From a historical standpoint, transfusion was introduced in healthcare to save (rather than to cure) people bleeding to death. Most frequently, the patients were young and healthy and suffered from different situations: women with difficult deliveries, trauma patients, complex surgery, injured soldiers on the battlefield, etc. In heroic times, the question was whether a donor could be standing at the patient's bedside, and later, the issue was how donated blood could be safely and swiftly transported from donors to the hospital [1]. These aspects were principally related to quantitative as well as operative procedures, and the paradigm was quite simple: having enough blood to compensate blood losses in order to save patients' lives. This patient-centered approach disregarded the possible complications of the rescue, even if some of those have been

* Corresponding author at: Faculty of medicine of Saint-Etienne, University of Lyon, 10, rue Tréfilerie, 42023 Saint-Etienne Cedex 2, France.

E-mail address: Olivier.garraud@univ-st-etienne.fr (O. Garraud). rapidly identified: the issue was a matter of life and death, and the benevolence for rescue was frontline.

This "lifesaving" approach (echoed by the message sent from many blood services: "Give blood, save life!") was rapidly extended to a life support; clinicians prescribe blood to patients presenting medical situations such as anemia (caused by a variety of disorders or being related to cancer treatment) [2,3]. Blood appeared as a new supportive care, raising novel hopes. But rapidly, it appeared that "total" or "whole" blood was not an ideal component and thus elicited the processing of novel blood components. Although the use of several separated blood components clearly complexified the build-up of inventories suited to serve patients timely and efficiently, it has also been associated with benefits. The difficulty in best serving patients is really enormous when considering the diversity of blood groups and the fast outdating of collected units. One solution of that problem was to extend the length of the storage of blood components allowing to reduce waste; this was still a patient-centered approach, but one that disregarded the donor benefit. Next, it appeared that investigating the infectious issues of the donated blood was immediately accepted as a standard 
procedure [4]; there again, this approach aimed to secure the donation, not to care for the donor.

A major switch dates back when economics became forefront. Despite the fact that in many countries, especially in high-income areas, blood is donated, a market of blood has emerged. Even though the blood was priceless, blood components were (very) costly [5]. To render this equation politically correct, it has been put forward that wasting blood (and thus public money) was unethical (individual's blood was also ascribed as a public resource). In this administration-focused era, blood transfusion services are managed like businesses and the imperative obligation to save both "source material" and costs has also created a suitable environment for the emerging concept of Patient Blood Management [6]. Industrialized countries are now obsessed with PBM, which even imposes the diktat over certain compassionate situations. Indeed, PBM comprises two branches: the first one being clearly patient-centered, taking into consideration his/her blood capital, iron stores, clotting ability; and the second one being society-focused, outlining that blood is a scarce resource, and that transfusion exposes to complications [7]. PBM often tends to highlight transfusion-associated risks over benefits. PBM has been adopted by the WHO in 2010 and initiatives promoting PBM have been launched so far in several organizations [8]. Of interest to note, PBM has largely been promoted-and still is-by certain anti-transfusion lobbies such as many industrial medicinal iron manufacturers, some plasma fractionation industries, and Jehovah's Witnesses. Opponents to transfusion often cite ethical concerns not to expose donors to blood donation-associated risks, and not to burden health expenditures with costly procedures (meaning that transfusion belongs to the long list of extra-budget expenditures). Indeed, transfusion is much more expensive than injectable iron, but considerably less than most chemo- and foremost immuno-therapies, making this health care definitely within acceptable daily expenditures. The paradox which associates with the latter is the frequently used sentence: "Blood is priceless, but transfusion has a cost".

The success of strategies that affect transfusion treatment should not be assessed only by the reduced cost and number of transfused blood components (as is common practice). It is far more important to monitor the successful outcomes of appropriate transfusions, taking into consideration the risk-benefit balance [9]. This information should be evidence-based. Authorities would be urged to finance well-designated clinical trials and physicians involved in-patient care using blood components to include their patients in such studies.

\section{The historical background of paradoxical issues related to blood transfusion}

The history of transfusion has been paved with good and evil, making this care profoundly humane. It is based upon the gesture of benevolent siblings to share their good health and assist the vulnerable, most frequently in exchange of nothing. Humanity in blood donation did not prevent the risk of infectious contamination, principally with pathogens that the donor was not aware of hosting. The early compassionate transfusion episodes were not necessarily safe. Physicians of the early years of the 20th century reported cases of transfusion-transmitted syphilis and malaria. It seems needless to digress around the disastrous HIV and HCV contaminations of hundred thousand of hemophiliacs and blood component recipients worldwide: this has been a humanitarian disaster and a medical nightmare for many professionals who were not aware of the risks at that time. Transfusion which was designed to save people happened to kill them [10]. Actually, the paradox is that all medicines are associated with hazards that even may lead to fatalities. Of course, this occurs after administration of blood components, but lethal accidents can also be caused by aspirin, acetaminophen (paracetamol) or by many other drugs that can be bought without any advice in pharmacies, drugstores or via the Internet.

Nowadays, blood components are ascribed to essential medicinal products according to WHO and other regulatory agencies [11]. In some countries, such as Switzerland, blood components are considered as drugs that have to be put on the market with the same rules as other drugs. Nevertheless, in many countries such as France, blood components are not simple drugs. This reflects the fact that transfusion may be off common rules and thus stand as "special" [12]; this is not only a therapeutic principle but also a transfer of humanity that could not be associated with harmful effects in people's mind (by essence, blood has to be "pure").

Another paradox-which is more recent-has been the development and implementation of pathogen reduction or inactivation technologies for labile blood components. These efficient technologies have been slowed down for nearly two decades and still endure reluctance from many practitioners and regulation bodies because they may alter and/or reduce some active principles that are normally present in blood and blood components. With the implementation of pathogen inactivation/reduction technologies, the safety paradigm has been changed from a reactive to a preventive approach, of value to prevent the risk of emerging infections $[13,14]$.

State responses to crises have been diverse, depending on the fundamentals in politics, in governing individual rights and in considering state intervention in public health. Centralized countries have unified blood services in one single national organization, slowly drifting from patient adapted medical approach to finally ending up with the creation of a state agency. This approach allowed revisiting the quality assurance principles and setup of hemovigilance. The later-after a quarter century of existence-still hesitates between quality in view of improvement of practices, and regulation of policies. As a matter of fact, hemovigilance-initially only (if not exclusively) devoted to the evaluation of risks and benefits of recipients-was progressively also addressed to donor health care [15].

For a long time indeed, blood collection facilities have been focused on improving quality and safety of blood components and providing sufficient blood supply for transfusion therapy. Despite the fact that the risk of iron deficiency in regular blood donors has been known for decades, interest in this issue has only been reactivated in recent years. Nowadays, many investigations have provided new insights leading to novel recommendations about decreasing this risk and improving the welfare and safety of blood donors. However, all potential problems related to donor health are not taken into consideration. For example, regular donors giving platelets or plasma by apheresis are massively exposed to DEHP, a banned chemical, except in transfusion medicine. Moreover, donors are not notified of the potential endocrinological consequences of chronic exposure to DEHP. Hemovigilance is still on its way to secure transfusion medicine as well as to provide useful data to manage both the risks and efficiency of blood components. In addition, many institutions today combine activities related to blood, tissues, cells, and organs, having acknowledged similarities relative to human origin, limited supplies, similar structure of the processes from donation to clinical applications and risks. Following these changes, the concept of hemovigilance also extends to other areas and results in biovigilance programs.

Approximately, at the time hemovigilance appeared, the precautionary principle has been formulated and was introduced in certain country laws. This precautionary principle was born after the Rio summit of 1992 and was influenced by four sanitary affairs, one of them the tainted blood scandal [16]. This precautionary 
principle has been per se an influential paradigm change; the associated paradox is that transfusion has been then regarded as a potential threat. The application of this principle culminated with the prevention of the transmission of the nvCJD prion (that has been so far been associated with only four acknowledged transfusion transmissions). Expensive measures have nevertheless been implemented; millions of donors have been deferred worldwide; transfused donors as well as donors who stay for months or years in the United Kingdom have been banned. All these measures were quite difficult to communicate and many regular donors were disappointed. As a result, the blood banks-and consequently the patients-, were deprived from the benefit of the generous gifts of many donors. The precautionary principle anxiously questioned both regular and potential donors about their good health. When considering hemovigilance data worldwide, the exclusion of donors who stayed in the United Kingdom or who have been transfused can be questioned. However, and based upon the precautionary principle, in certain countries such as France, persons having been transfused once are still banned from donating blood.

Recent history has shown that the new virus-SARS-CoV-2-may have an impact on transfusion safety [17]. However, strong scientific evidences indicating potential risk (or safety or transfused components) are missing. Despite the fact that SARS-CoV-2 is described as a "theoretical" and "unlikely" risk in transfusion medicine, it is capable of killing one million people on all continents in 7 months of the pandemic. Looking back, the rapid spread of the virus and its consequences seem to be partly the result of delayed reactions, non-transparency or insufficient preparedness of health systems. Lessons learned should serve to address future similar situations. The paradox of complexity is highlighted when considering blood groups. Blood transfusion was once imagined simple with three (then four) blood group (ABO) restrictions. Hundred years later, more than 360 red blood cell antigens have been identified, not all similarly important and relevant to transfusion medicine. The complexity is even greater when taking into consideration platelet antigens: their diversity is due to dozens of HPA specificities and millions of HLA type I allelic forms. Blood cells are immunologically complex and trigger-or may trigger-immunization, a complication that depends on a number of factors associated to donated blood characteristics, blood component processing, and recipient-linked parameters [18].

Nowadays, we have realized the complexity of transfusion therapy. This complexity is related to so many aspects as the diversity of blood group antigens, the immunological reactions in the recipients, the development of infectious diseases (related to bacteria, viruses, parasites or prions), the occurrence of adverse effects such as iron overload or other metabolic disturbances such as hyperkaliemia, to describe some of them [19].

However, if transfusion was non-existing yet, e.g. because of an impossibility of circumventing immune restrictions, and happened to be made possible as a consequence of a seminal discovery, it would have to pass the FDA and other agencies for authorized trials; this would be a nearly impossible task: too dangerous, too variable, too complex, too difficult to monitor and to follow up on the long term; additionally, the lack of reliable outcome or markers to monitor efficacy would render the filing nearly impossible. As a matter of fact, transfusion has been applied without efficacy and safety trials a centenary back...

\section{Transfusion is socially, anthropologically and ethically debated}

Hundred years after arm-to-arm blood transfer (husband to wife, father to child, soldier to soldier and sibling donations), the face of blood donations has completely changed. Storage of blood components allows the anonymity between the donor and the recipient permits the transport, even long-distance. Blood transfusion evolved from blood to blood components, allowing to organize immunologically diversified inventories, and, also very importantly, the time to test so many different parameters that have been introduced over the years to secure blood components.

The profile of donors has switched from an "average" human being to a "perfect" avatar to conform the "ideal" character of a donor, carved in the marble by generations of policy makers; this bible of contraindications is barely alleviated while additional deferral criteria abound (with consequences [20]).

In addition, governance agencies have developed an "ethical concept" based on voluntariness, anonymity, benevolence and not for-profit. This profile, nowadays ascribed to as voluntary non-remunerated donation (VNRD) according to the WHO, has emerged earlier on in countries such as France from post-WWII unions of blood donors. VNRD has imposed over other donation strategies; however, this expression of altruism bears in it both values and (often) judgements. For example, the reposition donation (blood donation within the family, or directed transfusion between a member of the community recruited as a donor for a non-anonymous patient) has been undervalued by most specialists in transfusion medicine of the rich countries, despite allowing to maintain blood transfusion in nearly half of the countries of the world that cannot set up ad hoc inventories with VNRD for a variety of reasons [21]. The ethical dispute is open: some individuals claim "It is not ethical to transfuse patients from non-VNRD" whereas other may say "It is not ethical not to transfuse patients who need blood, whatever the source of blood is". Ethics is a way to find solutions; ethics is not per se the solution.

Of notice however, an inverse correlation can be observed between the number of papers disserting on the value of ethical donation and the actual number of donations; from the 50's to 70 's, donation candidacies exceeded the capacity of blood collection, and blood collection exceeded the needs of populations, with hectoliters of blood being discarded without "ethical" alert. After the blood scandals (HIV, HCV), transfusion was charged with "capital sin" and blood donation became scarce. There is nowadays an inverse correlation between promotion expenditures (as a result of marketing blood donation) and results (number of units of blood collected). It seems that the amount of money necessary to promote blood donation in certain countries doubles every five years to achieve the same donation level. What is the role of associations of blood donors in this procedure? New associations emerge besides traditional blood donor organizations, with aggressive messages and very often biased commercials (they frequently specialize in component donations such as platelets and plasma). Aggressive communication clearly disrupts the possibility of voluntariness. Pressure is made on individuals: therefore, what is the true, scientifically correct and ethically honest language that has to be used to recruit new donors or to convince regular donors to maintain their donations? This defies traditional associations calling for new donors to come to blood donations. The difficulties endured by stakeholders of the blood donation/collection process are classically addressed by sociology methods to find solutions. This stands for a paradigm that is difficult to challenge. Some intellectuals shyly try to promote the exploration of anthropology tools. But wording is essential: the respect of the freedom of donors is essential, and new marketing tools clearly disrupt it, notably when culpability is used to maintain a pool of sufficient donors.

A major challenge of the present times is the plasma market for the manufacture of plasma derived medicines or drugs. The paradigm is that cellular components are not for-profit but that plasma which is fast renewable, is (some countries allow up to 36 L plasma donated per donor and per year). The plasma industry is among the most profitable ever, with a gross income increased by $10 \%$ annually. Much has been written on this subject that is 
particularly cleaving [5,22-26]; whatsoever, this is the subject of acute ethical and irreconcilable debates. Regarding the present dissertation, this points the subject of "big money" that has flooded the transfusion model, far from the brothers in arms generosity in heroic times.

Far from some angelic piece of mind from the 'Old Timers', this stresses out the state of links and conflicts of interest in the transfusion process and business. Has this been favored by a raise in administration rudeness? Is transfusion still a "charity"? Has the likely administration rudeness frozen attempts to reverse the business model to reinstall a charity model?

\section{Science, research and education}

Despite the huge progress that has been made in blood component preparation during the last century, one and the same concept is still applied today: bleeding patients should be transfused with "pure" blood. But pure blood does not exist anymore. It has been replaced by blood components, each characterized by particular properties. Each component has its own characteristics: cells have to be maintained in a liquid phase without clotting; each component should be characterized by a number of tests (the list of parameters is infinite) [27]. Each component should be safe in terms of infectious pathogens. Everything is done to increase the length of the conservation of each different component to allow to build-up an inventory. Unfortunately, none of these measures are preemptive of unpredictable complications that still occur when transfusing blood components. Not in force-yet-but in the pipeline-there is a paradigm change towards proactivity. Systems biology and metabolomics are tested to:

- detect and fish out emergent pathogens that may be potentially harmful;

- dissect proteomics of blood components-especially those derived from blood cells-to predict adverse reactions in the recipients;

- overview genomics of both recipients and donors in order to best match their blood and to further provide precision [transfusion] medicine $[28,29]$.

Next, disruptive technologies are also in the pipeline, such as in vitro engineered blood cells and modified cells to get around immunogenetic restrictions.

Despite the rising complexity of transfusion medicine, advances in all segments in the field and the growing presence of this discipline in other areas of medical science, transfusion medicine professionals are faced with the paradox of insufficient and nonstandardized education in their field, with different objectives, training approaches, etc. This results in inadequate practice learning and may compromise the safety of transfusion treatment. Education has long been given according to medical school traditional standards; more recently, novel education concepts have emerged that are still pending in most countries at least at the undergraduate level. Education in transfusion medicine should evolve alongside the revised paradigm of medical education as a whole [30]; proposals have been made by our reflection group, recently [31,32].

\section{A revisit of [transfusion] risk assessment}

In the late 1970 s and early 80 s thousands of people became infected with blood products contaminated with HIV and HCV. The tainted blood scandal resulted in paradigm change toward zerorisk policy, established the precautionary principle and generated enormous cost raise.
In the decades that followed, the implementation of numerous scientific and technological innovations and other measures in all aspects of transfusion medicine resulted in an improved quality and safety of transfusion treatment [33]. Data from most developed countries clearly show that the residual risk of transmission of pathogens that are routinely tested is very low [34], and the constant threat is posed by various new and emerging pathogens [35].

The dramatic reduction in the risk of transfusion-transmitted viruses, particularly HIV and HCV, has shifted the focus to other risks in transfusion medicine, primarily errors, bacterial contamination of blood components and immunological risks.

It became clear that not all risks can be foreseen and/or prevented and that zero-risk transfusion is an unachievable goal. The time has come to revisit not only the paradigm of the precautionary approach but the risk management in transfusion medicine as a whole [36,37].

As a consequence, the risk management approach that goes beyond quantitative risk assessment and takes into consideration the broader context (ethical issues, societal needs and expectations, health economics, risk tolerability, etc.) has been the subject of intensive debates by experts in transfusion medicine in recent years. The most important question is, however, whether society is now ready to tolerate some risks linked to transfusion, as it has been done for nearly all medicines? And if yes, which risks and which level of tolerance? Who will serve as evaluators of this new paradigm? The success of the decision-making process will largely depend on active participation of different stakeholders and on transparency.

The same stands for the revisit of donor health care. Overtime, the general feature has been that donating blood was welfare and prevented plethora, or at least totally harmless, to an at-risk procedure especially when extracorporeal circulation was established (apheresis); the case of iron store depletion was considered and debates about supplementing donors with iron, especially female donors, were set-up (with the ethical debate about treating by medical means and drugs-iron-a healthy person, contradictory to the principles of medicine if considered that every drug can be associated with side-effects, thus unbearable since the recipient was initially healthy). Some experts even ask the question of the extent to which we want to interfere with the lifestyle of otherwise healthy people, giving them dietary advice [38].

Remaining within the ethics debates, recipients were once called "beneficiaries". People at risk of dying from severe hemorrhage either benefited transfusions or died from the cause of the harm. Transfusion was a chance to survive. When transfusion happened to transmit deadly infections, and the risk-benefit analysis of administrating transfusions was within the grey zone, recipients could no longer be called beneficiaries as complications were no benefits. There again, there is a paradigm change, that is inlaid in the PBM approach.

Nevertheless, transfusion medicine is still in focus. The security of blood components is higher than ever, but a progressive loss of the intrinsic qualities of whole blood was the price to be paid. We have to face storage lesions, chemical alterations due to the presence of various solutions used to store blood, modifications of the proteins when pathogen inactivation procedures are used, modifications of the red blood cell membrane with cold storage, production of microparticles [27]. In summary, blood is no more blood when transfusion medicine is on stage.

\section{Concluding remarks on influential parameters}

In the era of lobbies in all domains of the public service to influence private interests, it is of interest to question the 


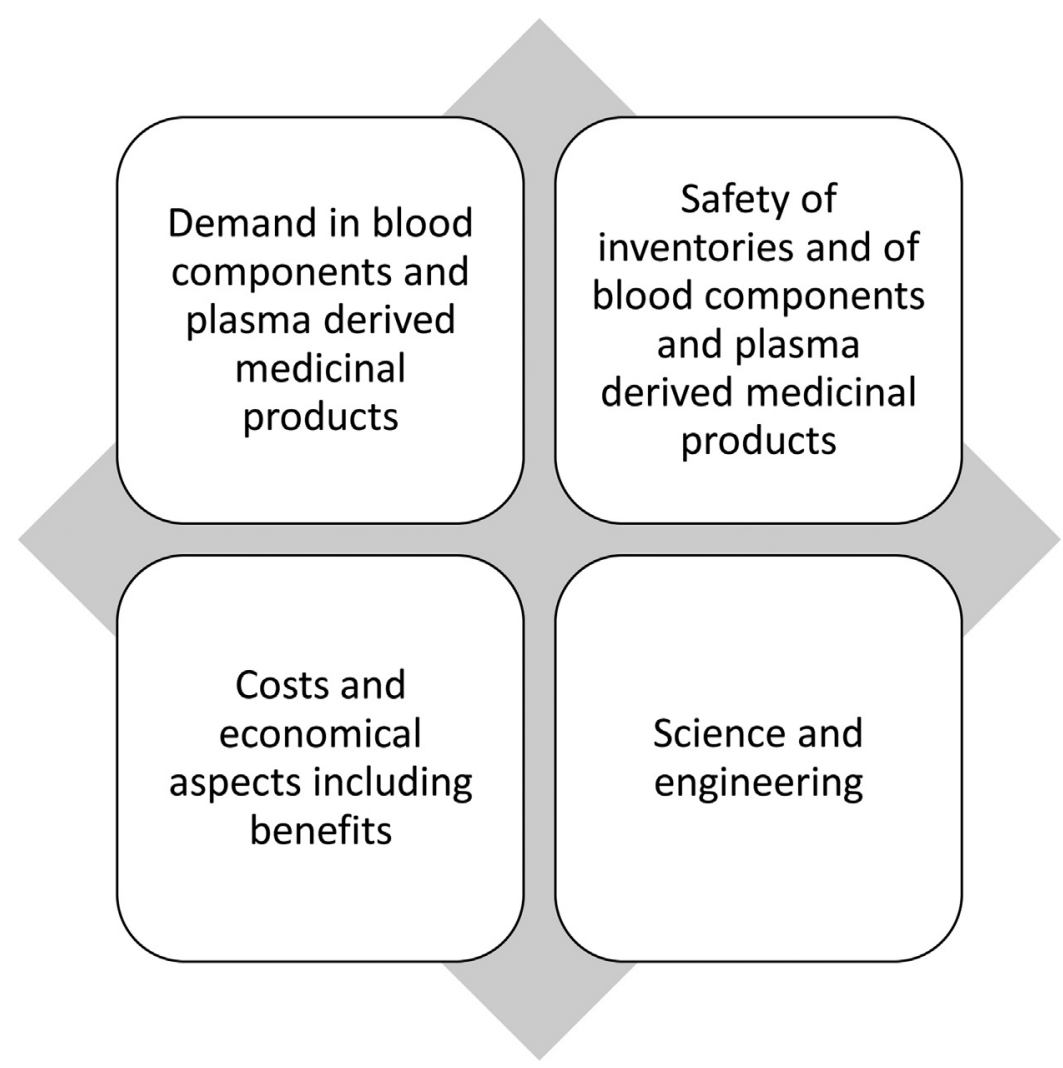

Fig. 1. The European and Mediterranean Initiative in Transfusion Medicine group's envision of the main drivers shifting the paradigms in transfusion medicine.

sources of influences in paradigm changes in transfusion medicine. Stakeholders are numerous: blood donors and associations and non-governmental organizations, professionals and health care workers, tax payers, regulators and legislators, administrators within the public service and also the private sector, industries, lobbyists (to the European Commission and European Parliament, the FDA, and to other policy makers), etc. For example, debates are particularly vivid regarding the plasma for fractionation issue: is it public good or private owning [24-26]?

What are drivers shifting the paradigms? Fig. 1 presents the "European and Mediterranean Initiative in Transfusion Medicine (EMITm)" group envision of the main drivers, irrespective of proportionality. Strengths seem to take over weaknesses, both being time-dependent; interestingly, it is this group's opinion that the outcome follows the course of ethics: what was acceptable at a time becomes totally unacceptable ten, twenty or thirty years later. Lobbies and influential groups-often controlled by financial interests-put emphasis on arrows, and exert a marketing of ideas, then endorsed by a majority of citizens. It appears to our group that more than ever it is important to maintain in depth reflection on what transfusion comes from, and what it is aimed at, under the light of humanities and philosophical ethics, to power arrows and limit the drifts as to maintain a sense of humanity.

To summarize the major paradigm changes, nowadays, the transfusion of blood has essentially vanished in economically wealthy countries, to be replaced by the transfusion of separate blood components. This has been at the expense of much lifeassociated symbols of the blood entity. However, like Phenix, transfusion of whole blood experiences a revival in high-income countries because blood brings added therapeutic value over split fractions in certain circumstances. What about the renewal of symbols?

\section{Disclosure of interest}

The authors declare that they have no competing interest.

\section{Acknowledgements}

Authors are indebted to Colleagues at the "European and Mediterranean Initiative for Transfusion medicine" (EMITm) for stimulating discussions and constant support.

\section{References}

[1] Giangrande PLF. The history of blood transfusion. $\mathrm{Br} \mathrm{J}$ Haematol 2000;110:758-67.

[2] Franchini M, Marano G, Mengoli C, Pupella S, Vaglio S, Muñoz M, et al. Red blood cell transfusion policy: a critical literature review. Blood Transfus 2017;15:307-17.

[3] Diamond LK. The history of blood banking in the United States. JAMA 1965;193:40-4.

[4] Seifried E, Mueller MM. The present and future of transfusion medicine. Blood Transfus 2011;9:371-6.

[5] Mercier Ythier J. The contested market of plasma. Transfus Clin Biol $2020 ; 27: 52-7$

[6] Thomson A, Farmer S, Hofmann A, Isbister J, Shander A. Patient blood management-a new paradigm for transfusion medicine? ISBT Science Series 2009:4:423-35

[7] Hofmann A, Farmer S, Shander A. Five drivers shifting the paradigm from product-focused transfusion practice to patient blood management. Oncologist 2011;16:3-11.

[8] Mueller MM, Van Remoortel H, Meybohm P, Aranko K, Aubron C, Burger R, et al. Patient blood management: recommendations from the 2018 Frankfurt consensus conference. JAMA 2019;321:983-97.

[9] Garraud O. How to reposition the benefice-risk balance to safely transfuse patients in non-vital situations? Transfus Clin Biol 2019;26:171-3.

[10] Spiess RD. Blood transfusion: the silent epidemic. Ann Thorac Surg $2001 ; 72: 1832-7$

[11] WHO. WHO models of essential medicines; 2019, https://www.who.int/ medicines/publications/essentialmedicines/en/. 
[12] Garraud O. Transfusion Clinique et Biologique"-what makes transfusion medicine and biology so special? Transfus Clin Biol 2017;24:403.

[13] Alter HJ. Pathogen reduction: aprecautionary principle paradigm. Transfusion MedRev 2008:22:97-102.

[14] Atreya C, Glynn S, Busch M, Kleinman S, Snyder E, Rutter S, et al. Proceedings of the Food and Drug Administration public workshop on pathogen reduction technologies for blood safety 2018. Transfusion 2019;59:3002-25.

[15] Wood EM, Ang AL, Bisht A, Bolton-Maggs PH, Bokhorst AG, Flesland O, et al. International haemovigilance: what have we learned and what do we need to do next? Transfus Med 2019;29:221-30.

[16] Wilson K, Atkinson KM, Fergusson DA, Brown A, Forster A, Murphy MSO et al Problems with precaution: the transfusion medicine experience. J Risk Res 2018;2017:1-13.

[17] Stanworth SJ, New HV, Apelseth TO, Brunskill S, Cardigan R, Doree C, et al. Effects of the COVID-19 pandemic on supply and use of blood for transfusion. Lancet Haematol 2020, http://dx.doi.org/10.1016/S2352-3026(20)30186-1 [published online ahead of print, 2020 Jul 3].

[18] Garraud O, Tariket S, Sut C, Haddad A, Aloui C, Chakroun T, et al. Transfusion as an inflammation hit: knowns and unknowns. Front Immunol 2016; 7:534.

[19] Garraud O, Sut C, Haddad A, Tariket S, Aloui C, Laradi S, et al. Transfusionassociated hazards: a revisit of their presentation. Transfus Clin Biol 2018;25:118-35.

[20] Davison TE, Masser BM, Gemelli CN. Deferred and deterred: a review of literature on the impact of deferrals on blood donors. ISBT Science Series 2020;15:3-10.

[21] Haddad A, Bou Assi T, Baz E, Samaha H, Hachem B, Feghali R, et al. Blood donations mode: assessment of the Lebanese model. Transfus Clin Biol 2019;26:341-5.

[22] Petrini C. Production of plasma-derived medicinal products: ethical implications for blood donation and donors. Blood Transfus 2014;12:389-94.

[23] Skinner MW, Hedlund Hoppe PA, Grabowski HG, Manning R, Tachdjian $\mathrm{R}$, Crone JF, et al. Risk-based decision making and ethical considerations in donor compensation for plasma-derived medicinal products. Transfusion 2016;56:2889-94.

[24] Farrugia A, Del Bò C. Some reflections on the code of ethics of the international society of blood transfusion. Blood Transfus 2015;13:551-8.

[25] Flanagan P. The code of ethics of the international society of blood transfusion. Blood Transfus 2015;13:537-8
[26] Farrugia A, Del Bò C. Reply to Flanagan "The code of ethics of the international society of blood transfusion" [Blood Transfus 2015;13:537-8]. Blood Transfus 2017;15:286-8.

[27] Garraud O, Tissot JD. Blood and blood components: from similarities to differences. Front Med 2018;5:84

[28] D'Alessandro A. From omics technologies to personalized transfusion medicine. Expert Rev Proteomics 2019;16:215-25.

[29] Yurkovich JT, Bordbar A, Sigurjónsson ÓE, Palsson BO. Systems biology as an emerging paradigm in transfusion medicine. BMC Syst Biol 2018;12:31.

[30] Seifried E, Schuettrumpf J, Mueller MM. Changing educational paradigms in transfusion medicine. ISBT Science Series 2011;6:89-95.

[31] Garraud O, Brand A, Henschler R, Vuk T, Haddad A, Lozano M, et al. Medical student education in transfusion medicine: proposal from the "European and Mediterranean initiative in transfusion medicine". Transfus Apher Sci 2018;57:593-7.

[32] Garraud O, Vuk T, Brand A, de Angelis V, Politis C, Haddad A, et al. Medical student education in transfusion medicine, part II: moving forward to building up a "Know How" education program in transfusion medicine for undergraduate medical students. Transfus Apher Sci 2020, http://dx.doi.org/10.1016/ j.transci.2020.102879.

[33] Devine DV, Chen D. A fresh look at measuring quality in blood components. ISBT Science Series 2014;9:148-54

[34] Laperche S, Tiberghien P, Roche-Longin C, Pillonel J. Fifteen years of nucleic acid testing in france: results and lessons. Transfus Clin Biol 2017;24 $182-8$.

[35] Whitaker BI, Walderhaug M, Hinkins S, Steele WR, Custer B, Kessler D, et al. Use of a rapid electronic survey methodology to estimate blood donors' potential exposure to emerging infectious diseases: application of a statistically representative sampling methodology to assess risk in US blood centers. Transfusion 2020, http://dx.doi.org/10.1111/trf.15941.

[36] Menitove JE, Leach Bennett J, Tomasulo P, Katz LM. Risk-based decision making. Transfusion 2014;54:753-7.

[37] Wilson K, Atkinson KM, Fergusson DA, Brown A, Forster A, Murphy MSQ et al. Problems with precaution: the transfusion medicine experience. J Risk Res 2018;2017:1-13.

[38] Van den Burg PJM, Magnusen K. Ethical aspects of blood donors and the recipients of their blood. J Blood Transfus 2012:606753. 